dull rubbing edge given to a conveniently sized pebble. Such, however, is seldom or never the case, and the class of implements, to which is given the above name, are as marked in their several peculiarities as is any form of stone implement with which we are familiar.

Having remarked the great abundance of these relics, I desire here more particularly to notice several specimens which are of more than ordinary interest. The illustrations $I, 2,3$, and 4 , are figures of the very smallest scrapers that I have seen; and what is more remarkable than their small size is the beauty of their finish and their symmetry. They are made of differently coloured jasper, were not found together or in the same neighbourhood, showing that they had different origins, and are not ex-

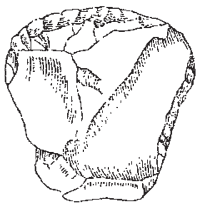

FIG. I.

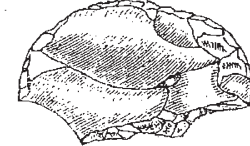

FIG 2. amples of the fancy of some eccentric chipper of flint implements, such as sometimes occur in masses of broken specimens and flakes that indicate the former site of an arrow-maker's labours.

Not one of these four small scrapers appears to be simply a flake, originally of this shape and subsequently chipped at the scraping edge; but the entire surfaces have undoubtedly been carefully wrought, and show that a small mass of the mineral has been worked to the shape and finish of the specimens, as now found. A quite common form of scraper is the base of an arrow or spear point which has been utilised by subsequently chipping the fractured end, so as to give it a bevelled edge; but the specimens here figured cannot be classed with these, inasmuch as there is nothing suggestive of the arrowpoint in their present shape, and unlike them, these four specimens have the under side smooth and slightly concave, a feature not found in the "made over" arrowheads.

Having seen that so much care was expended on these small scrapers, it is quite certain that these implements were put to some important use, but exactly what, it is difficult to determine. Certainly, in the dressing of the skins of our larger mammals they could be of no use, and of but little even when the skins of the smallest, such as squirrels, were used, which was probably seldom the case, as the ilarger quadrupeds were as easily obtained. The

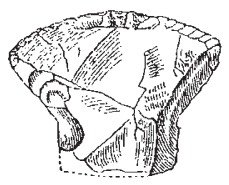

FIG. 3 .

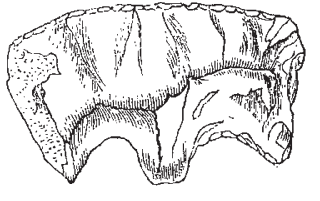

FIG. 4. skins of birds, if used as ornaments, would not need scraping to make them pliable; and I can only suggest that from the fact of having found traces of bone beads, in graves, made from sections of the long bones of wading birds, I have thought it probable that these small scrapers were used in rounding off the ends of such bone beads; and they might also have been used in the shaping and sharpening of the beautiful bone fish-hooks our aborigines were accustomed to make. Such uses would, of course, make the name "skin-scraper" inappropriate, as I am quite disposed to think it is.

Fig. 5 represents a very perfect specimen of the spoonshaped scrapers, such as are common in Europe, and by no means rare in the United States. Those found here, as a rule, are not so symmetrical as the specimen figured, and do not have the "bowl" or concave portion of the spoon so decidedly marked. Our New Jersey specimens have this under-surface generally plain, or but slightly concave; and uniform with the stem or handle of the implement. In the specimen figured this is not the case, and the spoon-shape is so pronounced as to suggest that it is a veritable spoon.

Fig. 5 has been chipped from a very pretty agate pebble, such as occur in the gravelly bed of the upper waters of the Delaware River; and it is an interesting

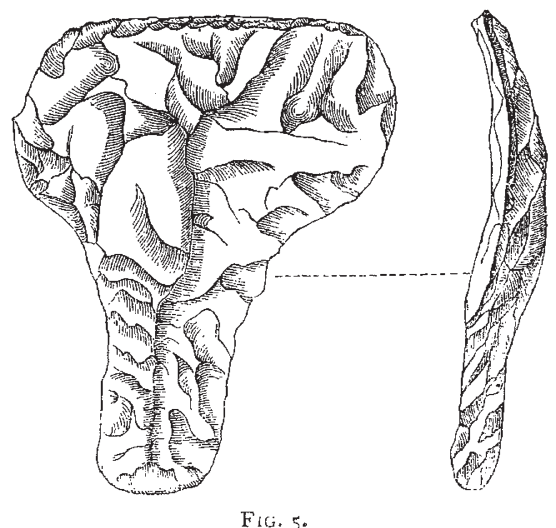

fact connected with this class of relics, that the majority are made of jasper, agate, and quartz, minerals the most difficult to shape, and certainly no better adapted to the ordinary uses of these implements-that of scraping the fat from skins.

One word in conclusion. Mr. C. C. Jones, jun., in his work on the "Antiquities of the Southern Indians," writes, under the head of "Scrapers" that "the spoon-shaped scraper of France and Switzerland is more pronounced in form and purpose than any implement of like character it has been my good fortune to find among the relics of the southern tribes."

It is curious that so much variation in the forms of their stone implements should exist in tribes nearly related, and but a few hundred miles apart. Judging from the specimens figured by the author quoted, scrapers were quite simple in their shape and finish; which, as we have seen, is the opposite of what we find in New Jersey, where as great a variety in shapes and sizes occur as exist in the various patterns of arrow-points. *

Trenton, New Jersey

Charles C. ABbot't

\section{THE RECENT BUTTER CASE}

$\triangle \mathrm{S}$ the case in connection with the Adulteration Act which we discussed in a leading article last week is of considerable importance, both from a scientific and a public point of view, we think it well to put the facts before our readers.

The following summary of the analytical results detailed in Court by the different chemists has been supplied us from a verbatim report of the proceedings before the magistrate at Southwark Police Court.

These results were given after the magistrate's decision had been delivered. They were entirely informal, and took the shape of a discussion, in which everyone appeared to act as his own counsel, and no attempt was made to establish or trace the identity of the samples.

* As authority for applying the term "scraper" to implements similar to Fig. 5, permit me to quote the late Prof. Jeffries Wyman ("Fifth Annual Report of Peabody Museum," 1872, P. 27). He writes, "The term scraper is applied to some of the implements just referred to (a collection from the author), because of their close resemblance to such as bear the same name from the Danish collections belonging to the Museum. They are characterised by having a circular or semi-circuiar flattened head, with a short projection which might serve as a handle, or for the purpose of attaching one They differ from the Danish implements chiefly in their much smaller size." 
Dr. Muter's analysis-

$\begin{array}{ll}\text { Water } & =15.00 \text { per cent, } \\ \text { Salt } & =3.96 ", " \\ \text { Curd } & =2.14 \%, \\ \text { Foreign fat } & =55^{\circ}, \\ \text { Butter fat } & =23.7 ",\end{array}$

The fat was thus made up of 30 per cent. of butter fat and 70 per cent. foreign fats. The fat had a melting point below that of butter, and yielded 93.3 per cent. of fatty acids. When examined by the microscope the butter was found to contain fat in a crystalline state, and the socalled curd consisted of vegetable matter, which was described as parenchyma. Finally, the butter was stated to be but slightly rancid.

Dr. Muter said that his standard for genuine butter was 88 per cent. of fatty acids.

Dr. Muter, who appears to have had sufficient of his sample to supply several of his friends, was supported in Court by his assistant Mr. De Konigh, Dr. Dupré, Mr. Wigner, and a microscopist.

Dr. Dupré and Mr. Wigner's Results.-Dr. Dupré found in the fat $94^{\circ} 05$ per cent. and Mr. Wigner $94^{\circ} 20$ per cent. fixed fatty acids, and the melting-point of the fat $4^{\circ} \mathrm{C}$. below that of genuine butter. On a microscopic examination of the butter, both found crystals of fat, which indicated that it had been fused. They also stated that the butter was practically free from rancidity.

Dr. Dupre was of opinion, from the results of his analysis, that there was a doubt whether the sample contained any butter at all; and Mr. Wigner considered that if it contained any butter-fat the quantity must be small, but indeed he thought it was foreign fat simply flavoured with caproic acid. He further stated that his standard for pure butter was 87.5 per cent. fatty acids.

Somerset House Results.- The portion of the sample retained by the inspector, and referred by the magistrate to Somerset House for analysis, weighed about 45 grammes, and it was stated that the experiments performed were not only of an exhaustive character, but were repeated in most instances.

The chemists there found as follows: $\rightarrow$

$$
\begin{aligned}
& \text { Water }=9.83 \text { per cent. } \\
& \text { Salt }=3.70 ", \\
& \text { Curd }=0.93 \quad " \\
& \text { Fat }=85.54 \quad "
\end{aligned}
$$

The fat gave a melting point of $33.3^{\circ} \mathrm{C}$, a density of ' 9053 at $100^{\circ}$ Fahr., and yielded 88.7 per cent. fatty acids, the latter being seven-tenths above Dr. Muter's standard.

The butter was found to be very rancid, and this rancidity would account for the slight excess of fixed fatty acids, it having been found by actual experiment that butter depreciates by exposure, and that there is a corresponding increase of the fixed fatty acids found in the fat.

On a microscopic examination the butter was found to be free from crystals of fat, and the only foreign substances present were a few particles of impurities consisting of hard wood and cotton thread.

The following are the results of the analysis of the fat of an article corresponding to "butterine," which was referred to in Court as having been examined in exactly a similar way as the sample in dispute :--

Fatty acids, $93^{\circ} 32$ per cent, melting-point, $25^{\circ} \mathrm{C}$, and density of fat at $100^{\circ} \mathrm{F} .={ }^{\circ} 90108$.

The processes followed by the different chemists for the analysis of the samples differed but little, but the chemists at Somerset House adopted an additional safeguard against error in saponifying the fats, by taking the density of the fat in the sample at a temperature of $100^{\circ} \mathrm{F}$.

The melting-point, the density of the fat, and the quantity of fixed fatty acids were clearly shown to be in complete accord, and these three results are certainly most important in their direct bearing on the accuracy of the analysis.

\section{NATURAL HISTORY OF ST. HELENA}

THE following extracts from a letter addressed to Dr. Hooker by Mr. Wollaston, who has been residing for some months in St. Helena for the purpose of investigating the insect fauna, can hardly fail to be interesting to students of geographical distribution:-

"Plantation House, St. Helena, Nov. 22, I875

"At this season of the year it is extremely difficult to obtain seeds, for the genuine native plants which are still not extinct, in addition to being extremely few in number, nearly all grow in places very difficult of access at a time when the upper ridges are nearly always covered with cloud, and only a certain proportion of them are showing any signs of active life (in the shape of flowers and seeds); but I have been able to collect three out of the four species of cabbage-trees, a Lobelic, two or three Wahlenbergias, and (best of all) the extremely rare Aster (or Commidendron) Burchelliz. This last is, I think, as nearly extinct as anything still living can be. Mr. Melliss says there is only one plant of it in the island; but in that he is wrong, for we counted two or three, in full blossom, in the same grove of the Aster gummifertus, in which he records the existence of his single individual. We have, however, seen it nowhere else, and it is decidedly on its last legs. Even the $A$. gummiferus is excessively rare, and I shall hope to get you seeds of it before we leave the island; as well as of the Commidendron robustum (the true 'gum-wood'). . . . The $A$. Burchellii is so rare that I have been drying you a few specimens, feeling that (as it may soon be gone altogether if we cannot persuade the islanders to spare it from their donkey-loads of firewood) you might, perhaps, like some fresh ones. ...

"The insect fora, although so extremely limited that I have not in nearly even three months collected more in Coleoptera than I50 species, still continues to keep up its character for eccentricity-ringing the changes on some half a dozen types (chiefly Rhyncophorous) to a marvellous extent. We seem indeed never to exhaust them, turning up new species almost every time that we can secure a hard day's work on the Composite ridge. Having ultimately to work them out, I take scores of specimens, and must have mounted carefully some six or seven thousand already."

T. D.

\section{NOTES}

THE following are the proposed movements of H.M.S. Chat: lentger:-She was to leave Valparaiso on Dec. IO, and arrive at the Falkland Isles on Jan. Io; leave on Feb. 6, arrive at Monte Video Feb. I8; leave Feb. 28, arrive at Tristan d'Aculnt March 20; leave March 25, arrive at Ascension April 7 ; leave April 14, arrive at St. Vincent May 5; leave May I2, and arrive in England June I2.

THe Senior Wrangler in this year's Cambridge Mathematical Tripos is Mr. Joseph Timmis Ward, of St. John's, son of the late Mr. Henry Ward, of Banbury. He was eancated at Rochester Cathedral Grammar School, under the Rev. $R$. Whiston. Mr. William L. Mollison, of Clare, the Second Wrangler, is a native of Aberdeen, and is the son of $\mathrm{Mr}$. W. Mollison, of that town. He was educated at the Grammar School and University of Aberdeen.

WE would call attention to the advertisement in to-day's NATURE by the Kew Committee, offering to the public greater facilities for the verification of instruments than have bitherto existed at Kew.

WE understand that the eminent onithologist, Dr. G. Hartlaub, of Bremen, has in preparation a new work on the Birds of Madagascar. This will be a considerable undertaking, as since 